\title{
BURNING MOUTH COMPLAINTS: CLINICAL CHARACTERISTICS OF A BRAZILIAN SAMPLE
}

Cibele Nasri ${ }^{1}$, Manoel Jacobson Teixeira ${ }^{2}$, Massako Okada², Gilberto Formigoni ${ }^{3}$, Gary Heir ${ }^{4}$, José Tadeu Tesseroli de Siqueira ${ }^{1}$

Nasri C, Teixeira MJ, Okada M, Formigoni G, Heir G, de Siqueira JTT. Burning mouth complaints: clinical characteristics of a brazilian sample. Clinics. 2007;62(5):561-6.

OBJECTIVE: Evaluation of the clinical characteristics of burning mouth complaints (BMC) in a series of Brazilian patients referred to a large teaching hospital.

MATERIALS AND METHODS: 66 patients with burning mouth complaints were evaluated through a standardized protocol. RESULTS: 56 women and 10 men were examined, ranging in age from 35-83 years. The primary location of the complaints was reported to be the tongue. Thirty-six patients reported a precipitating event. The mean VAS pain levels were 7.5 in women and $6.11 \mathrm{in} \mathrm{men.} \mathrm{The} \mathrm{average} \mathrm{estradiol} \mathrm{levels} \mathrm{in} \mathrm{women} \mathrm{were} \mathrm{low}(<13 \mathrm{pg} / \mathrm{ml}) ; 80 \%$ of all patients reported a concomitant chronic disease, $55 \%$ of all patients wore total dentures, $54 \%$ of all patients reported subjective xerostomia, $48 \%$ of all patients reported sleep disturbances and $66 \%$ reported phantom taste. No statistical differences were found between groups with or without a precipitating event in VAS: $(\mathrm{p}=0.139)$, in the Number of Words Chosen $(\mathrm{NWC})(\mathrm{p}=0.259)$ and Pain Rating Index $(\mathrm{PRI})(\mathrm{p}=0.276)$ sections of the McGill Pain Questionnaire (MPQ).

CONCLUSION: The existence of systemic comorbidities, self-reported sleep disturbances and taste alterations indicates possible correlations and the need for a careful systemic evaluation of each patient; there were no differences between patients with and without precipitating events.

KEY-WORDS: Burning mouth syndrome (BMS). Xerostomia. Orofacial pain. Facial pain. Atypical facial pain (AFP). Trigeminal neuralgia $(\mathrm{TN})$.

\section{INTRODUCTION}

Burning Mouth Syndrome (BMS) is classically referred to as a burning, painful, intra-oral condition with no observable mucosal lesions. ${ }^{1}$ Although the absence of intraoral lesions is one criterion for the diagnosis of BMS, there are other conditions such as intraoral post traumatic neuropathic pain, where there is also a burning feeling without

Preliminary findings of this paper were presented at the $9^{\text {th }}$ World Congress on Pain, August 22-27, 1999, Vienna, Austria.

1. Medical College, University of São Paulo - Dentistry

2. Medical College, University of São Paulo - Neurology

3. Medical College, University of São Paulo - ENT

4. University of Medicine and Dentistry of New Jersey - Dental School

Email: jtts@uol.com.br

Received for publication on May 25, 2007

Accepted for publication on June 17, 2007 any clinical findings. Therefore, other common pain producing conditions which manifest themselves as a burning sensation, such as peripheral neuropathy ${ }^{2}$ and pain of the masticatory muscles, ${ }^{3}$ must be considered in patients with burning mouth complaints. In addition, patients with chronic orofacial pain, such as trigeminal neuralgia, can develop burning mouth complaints after an oral surgical procedure or due to iatrogenic causes, ${ }^{4}$ making it even more difficult to distinguish burning mouth (BM) as a symptom from true BMS.

Recently, there has been a tendency to separate BMS in two groups: primary, or essential/idiopathic, and secondary, where the symptoms result from local/systemic pathological conditions. ${ }^{5}$ Despite this, there is no consensus on the most appropriate criteria for classifying BMS, nor is there an acceptable definition of the condition, especially 
if it is considered as a form of neuropathic pain.

The aim of this study was to evaluate the clinical characteristics of consecutive patients with spontaneous complaints of burning mouth in the absence of mucosal lesions referred to a large teaching hospital, in order to better understand the possible etiologies of burning mouth complaints.

\section{PATIENTS AND METHODS}

Sixty-six consecutive patients with spontaneous burning mouth complaints were evaluated at an orofacial pain group, during the period of March, 1999 - June, 2002. The study group represents $4.5 \%$ of all new patients with orofacial pain complaints examined by the Orofacial Pain Clinic during that time.

Patients with clinical signs of pseudomembranous or erythematous oral candidiasis and patients that had recently obtained dental prosthetic treatment (dentures) were excluded from the study.

A standardized diagnostic protocol was applied to all patients equally by a trained group of professionals, and panoramic radiographs of the jaw were taken. The protocol consisted of an interview and systematic evaluation of cervical, cranial, facial, dental and other oral structures according a standardized orofacial pain questionnaire used for all patients with orofacial pain. A supplemental questionnaire specific for burning mouth complaints was also used, which included: a) demographic characteristcs of the patient; b) burning mouth complaints (location, intensity, quality, duration, time course of pain), c) the presence of precipiting factors of the burning mouth, d) dental characteristics, e) palpation of the masseter muscles, and f) presence of comorbidities.

The serological evaluation included:

1. Complete hematological, hormonal, glucose and iron levels.

2. Estrogen levels measured according to the references of the hospital's central laboratory, where the analysis was performed. Normal levels for post-menopausal woman were up to $35 \mathrm{pg} / \mathrm{ml}$.

Microbiological analysis for Candida was performed.

Pain intensity ratings were reported using a VAS score with a rating scale of $0-10(0=$ no pain and $10=$ worst pain).

The Portuguese version of the simplified McGill Pain Questionnaire (MPQ) was used for pain dimensions. ${ }^{6}$

\section{Statistical analyses}

Patients were stratified by gender and comparisons were conducted for the general characteristics of the sample. The chi-square statistic (Fisher's exact test for small expected frequency) was used to compare proportions. The MannWhitney test was used to differentiate the groups with and without precipitating events. The data were analyzed using SPSS 10.0 for Windows.

This study was approved by the Ethics Committee of the hospital, and the patients gave their informed consent.

\section{RESULTS}

The general characteristics of the sample are outlined in Table 1. Sixty-six subjects with complaints of burning mouth were evaluated. Fifty-six $(84 \%)$ were female, and $10(15 \%)$ were male (ratio 5.6:1), with age ranging from 35 to 83 years old (mean age of women $=62.35 \mathrm{y}$. men $=$ 60.61 y.). Duration of complaints ranged between 1 to 360 months, while the VAS comparison showed an overall mean level of pain of 6.9 (mean); $7.5 \mathrm{~m}$ in women, and 6.11 in men.

Thirty subjects (45\%) reported only one pain location: the anterior tongue in $18(60 \%)$, posterior tongue in 4 $(13 \%)$, lateral border of the tongue in $1(3 \%)$, buccal mucosa in $5(16 \%)$ and palate in $2(6 \%)$; thirty-six $(54 \%)$ reported pain in multiple sites of the mouth: the anterior

Table 1 - General characteristics of the sample $(n=66)$

\begin{tabular}{lll}
\hline Gender & Female: 56 & Male: 10 \\
Median Age (year) & $62.35(35$ to 83$)$ & $60.61(39$ to 73$)$ \\
Duration of burning (median) & $1 \mathrm{~m}$ to $360 \mathrm{~m}(39.42 \mathrm{~m})$ & $4 \mathrm{~m}$ to $78 \mathrm{~m}(29.44 \mathrm{~m})$ \\
Self-report sleep disorders & Yes:39 & Yes: 4 \\
& No: 23 & No: 6 \\
Taste alterations & Bitter: 22 patients & Bitter: 1 patients \\
& Sour: 10 patients & Sour: 1 patients \\
& Salty: 9 patients & Salty: 0 patients \\
VAS & Sweet: 1 & Sweet: 1 patient \\
Comorbidities & Female: 7.5 & Male: 6.1 \\
& Yes: 47 & Yes: 6 patients
\end{tabular}


tongue in $32(41 \%)$, posterior tongue in $18(26 \%)$, lateral border of the tongue in $19(27 \%)$, palate in 18 (26\%), lips in $19(27 \%)$ and buccal mucosa in 17 (24\%).

Other complaints reported in this group included: subjective xerostomia in $36(54 \%)$ patients; phantom taste in $45(68 \%)$ patients, with 9 reporting a salty taste $(20 \%), 23$ bitter (52\%), 11 sour $(25 \%)$ and 2 a sweet taste (4\%); and hypogeusia in $2(3 \%)$ patients. Thirty-three $(50 \%)$ patients in this sample underwent a prior treatment for this condition.

Neither bone nor dental alterations were observed in the panoramic radiographs of the jaws.

Hormonal findings. Among the women, 52 (92\%) were postmenopausal, and estradiol levels were low in these patients (average $<13 \mathrm{pg} / \mathrm{ml}$ ).

Comorbidities. Fifty-three $(80 \%)$ patients reported the following concomitant chronic diseases: gastric disturbance in $41(77 \%)$ patients, hypertension in 16 (20\%), psychiatric disturbances in $6(11 \%)$, cardiopathies in $6(11 \%)$, fibromyalgia in $4(7 \%)$, diabetes mellitus in $4(7 \%)$, hypothyroidism in $3(5 \%)$, rheumatoid arthritis in $3(5 \%)$, cerebrovascular event in $2(3 \%)$, trigeminal neuralgia in 2 $(3 \%)$, respiratory disturbances in $1(2 \%)$, breast cancer in $1(2 \%)$, hepatitis in $1(2 \%)$, and intestinal cancer in $1(2 \%)$ patient.

Subjective sleep disturbances. Forty three patients (65\%), 39 women and 4 men, self-reported sleep disturbances.

Candidiasis. Thirty-nine (59\%) were positive for Candida in a microbiological examination, although none of the patients presented with clinical signs of candidiasis.

Dental condition and masseter muscle tenderness. The dental characteristics in this sample were (Table 2): complete dentures in $7(10 \%)$ patients, partial dentures in
Table 2 - Dental condition

\begin{tabular}{lccc}
\hline & $\begin{array}{c}\text { Male N=10 } \\
(15 \%)\end{array}$ & $\begin{array}{c}\text { Female N=56 } \\
(84 \%)\end{array}$ & Total N=66 \\
\hline Complete Denture & 1 & 6 & 7 \\
Partial Denture & 6 & 11 & 17 \\
Total Edentulous & 2 & 28 & 30 \\
Edentulous in one arch & 1 & 11 & 12 \\
\hline
\end{tabular}

$17(25 \%)$, totally edentulous in $30(45 \%)$, edentulous in one arch in $12(18 \%)$, and tenderness upon palpation of the masseter muscle in $22(33 \%)$.

Precipitating events. Thirty patients (45\%) self-reported the following precipitating event for their burning complaints: post denture insertion in 7 (30\%) patients, stressful life events in $7(23 \%)$, dental or periodontal surgery in $5(21 \%)$, local mechanical trauma in $4(17 \%)$, facial trauma during a motor vehicle accident in $2(8 \%)$, bilateral mandibular anesthetic block in $1(4 \%)$, post-endoscopy in $1(4 \%)$, post-radiation therapy in $1(4 \%)$, rheumatoid arthritis in $1(4 \%)$ and antibiotic therapy in $1(4 \%)$.

The site frequencies for $\mathrm{BM}$ without a precipitating event vs. BM with a known precipitating event were: anterior tongue, $29(80 \%)$ and $22(73 \%)$ patients, respectively; posterior tongue, $12(33 \%)$ and $11(36 \%)$; lateral border of the tongue, $9(25 \%)$ and $10(33 \%)$; lips, $10(27 \%)$ and $9(30 \%)$; palate, $11(30 \%)$ and $12(40 \%)$; and buccal mucosa, $6(16 \%)$ and $13(43 \%)$.

No statistical differences were found between either group in VAS ( $\mathrm{p}=0.139$ ) (Table 4$)$, in the Number of Words Chosen (NWC) $(\mathrm{p}=0.259)$ and Pain Rating Index (PRI) $(\mathrm{p}=0.276)$ sections of the McGill Pain Questionnaire (MPQ). The results of the MPQ for both groups, with or without precipitating events, are outlined in Table 3.

Table 3 - Intensity and distribution of pain (VAS): Precipitating (PE) and No Precipitating Events (NPE)

\begin{tabular}{|c|c|c|c|c|c|c|c|}
\hline & VAS)* & Mean age & Women & Men & One site & Multiple sites & $\begin{array}{l}\text { Mean duration } \\
\text { of pain }\end{array}$ \\
\hline$\frac{\mathrm{PE}}{(\mathrm{n}=30)}$ & 8.0 & 62.53 & 28 & 2 & 17 & 20 & $\begin{array}{c}34.76 \\
2 / 204 \mathrm{~m}\end{array}$ \\
\hline $\begin{array}{l}\text { NPE } \\
(\mathrm{n}=36)\end{array}$ & 7.0 & 58.6 & 28 & 8 & 13 & 16 & $\begin{array}{c}42.97 \\
1 / 360 \mathrm{~m}\end{array}$ \\
\hline
\end{tabular}

$* \mathrm{p}=0.139$

Table 4 - McGill Pain Questionnaire: Precipitating (PE) and No Precipitating Events (NPE)

\begin{tabular}{lcccccc}
\hline & Sensory & Affective & Evaluative & Misc. & $\begin{array}{c}\text { Number of Words Chosen (NWC) } \\
(\text { mean)** }\end{array}$ & $\begin{array}{c}\text { Pain Rating Index (PRI) } \\
(\text { mean)*** }\end{array}$ \\
\hline PE $(\mathrm{n}=30)$ & 13.8 & 6.73 & 1.93 & 4.33 & 26.8 & 57.8 \\
NPE $(\mathrm{n}=36)$ & 12.3 & 6.2 & 1.9 & 4.8 & 24.85 & 48.85 \\
\hline
\end{tabular}

$* * \mathrm{p}=0.259, * * * \mathrm{p}=0.276$ 


\section{DISCUSSION}

This study shows that the clinical characteristics of the patients evaluated are similar to those reported in the current literature, ${ }^{7,8}$ i.e., the tongue is the primary site of intraoral burning (91\%), and there is a high prevalence in women (ratio 5.6:1) in the post-menopausal period (mean age of 60.61 years). It is possible that older females in the post-menopausal period are at a higher risk for burning mouth complaints. ${ }^{9}$ In this sample, $92 \%$ of women presented low levels of estrogen, considered a risk factor for burning mouth syndrome, ${ }^{10}$ although the role of estrogen is still controversial.

The important findings of this data include the great variety of precipitating events reported by the patients with traumatic neuropathic pain, as well the high number of patients with phantom tastes and self-reported sleep abnormalities related to chronic pain and peripheral neuropathies. ${ }^{2,11,12}$ The understanding of various etiologies may lead to a more accurate differential diagnosis. This is important, and is reinforced by the high number of comorbidities found in this sample. Patients with diabetes mellitus can present with burning mouth complaints as a complication of the disease (diabetic neuropathy) ${ }^{13}$. The same situation may occur after radiation therapy of the head and face. ${ }^{14}$ In addition, patients with fibromyalgia may present with a lowered pain threshold and often report a burning sensation of the mouth or skin. ${ }^{15}$

Similarly, the high frequency of gastric abnormalities in this sample indicates the need for a future evaluation study, since esophageal reflux and dysphagia can be associated with oral burning. ${ }^{16}$

Medications play an important role in reducing salivary flow, and some have a direct effect on saliva, such as those with an anticholinergic action. Patients with systemic disease or elderly patients may use medications that lead to diminished salivary flow, and especially when this is associated with local conditions (wearing prosthesis, parafunctional habits, etc.), it may cause burning mouth.

The observation of patients with tenderness of the masseter muscles upon palpation suggests the need for a complementary evaluation, since edentulous patients utilizing ill fitting prostheses and those who present with masticatory myofascial pain may also present with burning mouth complaints. ${ }^{17}$ This is an important consideration, since there is high prevalence of edentulous individuals in populations such as in Brazil. ${ }^{18}$ Inappropriate or unstable prostheses can cause repetitive trauma to the oral mucosa, especially when they are associated with xerostomia. Consequently, mechanical irritation, such as that provoked by prostheses or any sharp angles on the dental surfaces, should be eliminated, as should any dental and periodontal infections, as these can generate, amplify and perpetuate the painful condition. ${ }^{19}$

Although this study was conducted in a tertiary hospital and therefore reflects the complexity of its patients (as can be observed by the comorbidities reported), the data show that there are numerous local or systemic diseases that may cause burning mouth, and the absence of oral mucosa lesions alone is not enough to make a final diagnosis. There are several local and systemic factors that may contribute to a burning mouth complaint. Thus, a careful assessment and as needed, a multidisciplinary approach, should be considered in patients with burning mouth complaints. ${ }^{20}$

In conclusion, the presented data showed no differences between patients with and without precipitating events. There was a high incidence of post-menopausal women in the studied group. The systemic and local findings, selfreported sleep disturbances and taste alterations confirm the need for differential diagnoses from other painful peripheral and central conditions that manifest in a similar manner.

\section{RESUMO}

Nasri C, Teixeira MJ, Okada M, Formigoni G, Heir G, de Siqueira JTT. Queixas de ardência bucal: características clínicas de amostra brasileira. Clinics. 2007;62(5):561-6.

OBJETIVO: Avaliar as características clínicas de pacientes brasileiros com queixas de ardência buccal atendidos em um hospital escola.
MÉTODO: 66 pacientes com queixas de ardência bucal foram avaliados através de exame padronizado para esse tipo de queixa.

RESULTADOS: 56 mulheres e 10 homens foram examinados consecutivamente. As idades variaram de 35-83 anos. A localização das queixas foi principalmente na língua e 36 pacientes relataram algum evento precipitante. A Esca- 
la Visual Analógica (EVA) a intensidade da ardência (dor) foi: mulheres 7.5 (média) e homens 6.11 (média). Os níveis de estradiol foram baixos $(<13 \mathrm{pg} / \mathrm{ml})$; $80 \%$ dos pacientes relataram doença crônica associada, 55\% usavam dentadura; 54\% relataram xerostomia subjetiva; $48 \%$ distúrbios subjetivos do sono e $66 \%$ gosto fantasma. Não houve diferença da intensidade da EVA $(p=0.139)$ ou dor pelo questionário McGill NWC ( $\mathrm{p}=0.259)$ and PRI $(\mathrm{p}=0.276)$, entre os grupos com e sem eventos precipitantes.
CONCLUSÕES: A existência de doenças crônicas associadas, o auto-relato de distúrbios do sono e as alterações de paladar indicam necessidade de avaliação sistêmica cuidadosa nesses pacientes; não houve diferenças entre os grupos com e sem evento precipitante.

UNITERMOS: Síndrome da Ardência Bucal (SAB). Xerostomia. Dor Orofacial. Dor Facial. Dor Facial Atípica (DFA). Neuralgia Trigeminal (NT).

\section{REFERENCES}

1. Grushka M. Clinical Features of burning mouth syndrome. Oral Surg Oral Med Oral Pathol 1987;63:30-36.

2. International Association for the Study of Pain (Subcommittee Taxonomy). Classification of chronic pain: descriptions of chronic pain syndromes and definitions of pain terms. Seattle: IASP Press; 1994.

3. Svensson P, Kaaber S. General health factors and denture function in patients with burning mouth syndrome and matched control subjects. J Oral Rehabil 1995;22:887-895.

4. Siqueira SRDT, Nobrega CM, Valle LBS, Teixeira MJ, Siqueira, JTT. Idiopathic Trigeminal Neuralgia: Clinical aspects and dental procedures. Oral Surgery Oral Medicine Oral Pathology Oral Radiology and Endodontics 2004;98:311-315.

5. Scala A, Checchi L, Montevecchi M, Marini I. Update on Burning Mouth Syndrome: Overview and patient management. Crit Rev Oral Biol Med 2003;14:275-291
6. Pimenta CAM, Cruz DALM, Barbosa C, Teixeira MJ. Versão rduzida do Questionário de Dor McGill para a Língua Portuguesa. In: III Simpósio Internacional de Dor, Programa Oficial São Paulo 1997; Grupo de Estudos da Dor do HC-FMUSP, p.26.

7. Zakrzewska JM. Burning mouth. In: Zakrzewska JM, Harrison SD, editors. Pain research and clinical management. Amsterdam: Elsevier; 2002;14:371-384.

8. Ship, JA, Grushka, M, Lipton, JA, Mott, AE, Sessle BJ, Dionne RA. Burning mouth syndrome: an update. Jam Dent Assoc, 1995;126:842853.

9. Bergdahl M, Bergdahl J. Burning mouth syndrome: prevalence and associated factors. J Oral Pathol Med 1999;28:350-354.

10. Forabosco A, Criscuolo M, Coukos G, Uceli E, Weinstein R, Boticceli A, Volpe A. Efficacy of hormone replacement therapy in post menopausal women with oral discomfort. Oral Surg Oral Med Oral Pathol 1992;73:570-574 
Nasri C et al.

11. Mott EM, Grushka M, Sessle B. Diagnosis and management of taste disorders and burning mouth syndrome. Dental Clinics of North America 1993;37:33-71.

12. Grushka M, Bartoshuk LM. Burning Mouth Syndrome and Oral Dysesthesias. The Canadian Journal of Diagnosis 2000;99-109.

13. Carrington S, Getter L, Brown RS. Diabetic neuropathy masquerading as glossodynia. J Am Dent Assoc 2001;132:1549-1551.

14. Niedermeir W, Huber M, Fischer D, Beier K, Muller N, Schuler R. Significance of saliva for the denture-wearing population. Gerodontology 2000;17:104-118.

15. Fricton J, Carlson P, Messner R. Rhodus NL. Oral Symptoms associated with fibromyalgia syndrome. J Rheumatol. 2003;30:1841-5.
16. Rhodus, NL, Carlson CR, Miller CS. Burning mouth (syndrome) disorder. Quintessence 2003;34:587-593.

17. Siqueira JTT, Ching LH. Dor Orofacial em pacientes desdentados totais com disfunção temporomandibular: Estudo retrospectivo longitudinal. Rev Paul Odontol 1999;3:32-37.

18. Ministério Da Saúde do Brasil. Levantamento Epidemiológico em Saúde Bucal, Brasil, zona urbana, MS Brasil, 1986, p.110-115.

19. Nasri C, Teixeira MJ, Siqueira JTT. Clinical Study of the General Characteristics of Patients with Burning Mouth Complaints. Jornal Brasileiro de Oclusão, ATM \& Dor Orofacial 2002;2:265-352

20. Nasri C, Oliveira MFV, Formigoni G, Teixeira MJ, Siqueira JTT. Burning mouth - a multidisciplinary assessment. Abstracts of 9th World Congress of Pain, Seattle: IASP Press 1999;306-307. 